\title{
Serum antibody responses to mycobacteria in leprosy patients and their contacts
}

\author{
I A CREE, W C SMITH \& J SWANSON BECK \\ Departments of Pathology and Community Medicine, University of \\ Dundee, Ninewells Hospital and Medical School, Dundee, DDI \\ 9SY, Scotland, UK.
}

\section{Accepted for publication 27 July 1988}

Summary The aim of this descriptive study was to investigate the relationships between serum antibody responses to different mycobacteria in leprosy patients and contacts. The results of ELISAs for serum antibody against whole mycobacteria (Mycobacterium leprae, M. tuberculosis, and M. scrofulaceum) were compared with the results of an $M$. leprae-specific ELISA for antibody against an epitope of PGL1. The IgG response was found to be predominant in ELISAs for antibody directed against whole $M$. leprae, while the IgM response was greatest in the assay for antibody against PGLl. Some healthy hospital workers were found to have appreciable levels of IgM anti-PGL1. Since infection in this group is unlikely, chronic exposure may result in humoral responses to PGL1 in addition to subclinical leprosy. None of the ELISAs studied were able to give greater than a $55 \%$ sensitivity at $95 \%$ specificity and none were considered suitable for serodiagnostic use.

Significant correlation was found between the results from the whole mycobacterial ELISAs, which could be explained on the basis of cross-reaction between antibodies directed against common antigens. However, similar correlations were found between the results of the $M$. leprae-specific ELISA and the assay for antibody against whole $M$. tuberculosis and $M$. scrofulaceum which were greater than those for antibody against whole $M$. leprae. Infection with $M$. leprae may produce general stimulation of immunological memory for common mycobacterial antigens resulting in responses to antigens belonging to other mycobacteria to which the host has been exposed previously.

\section{Introduction}

Humoral responses in leprosy were first studied by complement fixation, ${ }^{1,2}$ haemagglutination ${ }^{3,4}$ and immunodiffusion. ${ }^{5,6}$ In recent years, a number of other techniques for the detection of antibody directed against whole $M$. leprae or antigens derived from leprosy bacilli have shown some promise as serodiagnostic tests for leprosy. These include a qualitative fluorescent antibody (FLA-ABS) test, ${ }^{7}$ and ELISA or RIA methods ${ }^{8-10}$ which use whole $M$. leprae as antigen. Tests using whole mycobacteria rely upon absorption of the sera for their specificity and are not as reliable for 
serodiagnosis as ELISAs or RIAs using antigens specific to M. leprae,$^{11,12}$ but whole mycobacterial assays have proved usef ul in descriptive studies of humoral immunity in leprosy patients.

The highest levels of antibody to antigens of $M$. leprae are generally found in lepromatous patients, while few tuberculoid patients or contacts have positive titres, although there is considerable variation in the levels within each group on the Ridley-Jopling scale. Antibody is produced against a wide variety of antigens in the serum of leprosy patients. ${ }^{13-16}$ The majority of these antigens cross-react with antibody to other mycobacteria, but have nevertheless proved usef ul in studies of immunity in leprosy using radioimmunoassay (RIA) ${ }^{6,11,17}$ Species-specific antigens such as the phenolic glycolipid PGLl which coats the surface of the leprosy bacillus have been described more recently. ${ }^{18}$ The highest titres of antibody to PGL1 occur in lepromatous patients and the response is predominantly of the IgM subclass. ${ }^{19}$ Since IgM responses are thought to occur at an early stage in the development of leprosy, ${ }^{20}$ serodiagnosis of leprosy seemed to be eminently feasible. A number of newer ELISAs based on synthetic glycoconjugates which mimic the immunogenic epitope of $\mathrm{PGL1}^{21,22}$ or monoclonal antibody inhibition ${ }^{23-25}$ are now available. The more recent assay methods are said to provide good separation of healthy individuals from patients and are not confused by the presence of immunity to other species of mycobacteria, although their ability to detect subclinical or indeterminate leprosy under field conditions has yet to be proven. ${ }^{16}$

The aim of most recent studies of antibody levels in the serum of leprosy patients and their contacts has been the production of a diagnostic test for leprosy at a subclinical stage, before nerve damage and transmission of the disease have occurred. ${ }^{6,26}$ In some studies, an additional objective has been to identify those members of a population who are at risk of leprosy. The object of the present investigation was to compare serum antibody levels against several different mycobacteria in leprosy patients and their contacts with an $M$. leprae-specific assay for antibody against PGL 1 , to clarify the role of the humoral response in the pathogenesis of the disease. Since cross-reacting antibodies against antigens shared by several species of mycobacteria are part of the humoral immune response to $M$. leprae and may be of pathological significance, the lack of strict serological specificity of the methods used for their detection was not a major consideration.

\section{Materials and methods}

\section{SUBJECTS}

During a field study in the North-east of Bangladesh in 1986, a total of 253 subjects were examined, as described previously. ${ }^{27}$ The subjects were divided into 5 groups: 52 untreated leprosy patients, 53 treated leprosy patients, 78 household contacts of untreated patients, 20 hospital contacts, and 50 indigenous 'control' subjects. Since the control group was drawn from a population with a high prevalence of leprosy, it should be noted that many will have been exposed to leprosy and that a few might even have subclinical leprosy. Serum samples were obtained by venepuncture and preserved for transport back to Scotland by the addition of sodium azide to a final concentration of $0.5 \mathrm{mg} / \mathrm{ml}$ serum. Only 10 of the serum samples were lost in transit. Skin biopsies were taken from 41 of the untreated leprosy patients and from 11 of the treated leprosy patients to confirm the diagnosis and their Ridley-Jopling classification. Of the 52 new patients, 4 were classified as TT, $23 \mathrm{BT}, 1 \mathrm{BB}, 9 \mathrm{BL}$, $8 \mathrm{LL}$, and $7 \mathrm{Idt}$. The treated group consisted of $29 \mathrm{BT}, 1 \mathrm{BB}, 9 \mathrm{BL}$, and $14 \mathrm{LL}$ patients. The serum samples brought back from Bangladesh were centrifuged and divided into aliquots which were frozen at $-20^{\circ} \mathrm{C}$ if they were not required immediately.

\section{ELISA METHODS}

Two assays were used during this study: the first was intended to detect all antibody directed against the external surface of whole mycobacteria, while the second was an $M$. leprae-specific assay which has been shown to detect antibody directed against a single epitope of PGL $1 .{ }^{21}$ 
A serum standard composed of equal quantities of serum from 5 multibacillary patients was used as a positive control in screening experiments in which up to 264 samples were assayed simultaneously. Twelve sera from healthy Scottish volunteers were used as leprosy-negative controls. All of the sera were assayed for IgA; IgG and IgM antibodies against whole M. leprae and against the BSA glycoconjugate. In further experiments, whole $y$-irradiated $M$. scrofulaceum and $M$. tuberculosis were substituted for $M$. leprae and all of the sera were assayed for polyvalent antibody activity against these mycobacteria.

\section{ELISA with whole, y-irradiated mycobacteria}

An ELISA method for detecting antibody against whole $M$. leprae was developed from published methods. ${ }^{9,19,28}$ Polystyrene ELISA plates were treated with $0 \cdot 1 \%$ gelatine prior to coating on the bacilli to reduce the background absorbance and improve bacterial adhesion to the plates. Whole $y$ irradiated mycobacteria of 3 species (armadillo-derived M. leprae batch CD67, M. tuberculosis, strain H37Rv and M. scrofulaceum) were donated for this study by DR R J W Rees (Division of Communicable Diseases, Clinical Research Centre, Harrow). The whole bacilli at a concentration of $2 \times 10^{7} / \mathrm{ml}$ were suspended in a volatile ammonium carbonate buffer $(\mathrm{pH} \mathrm{8.2)}$ and dried onto the plates overnight at $37^{\circ} \mathrm{C} .{ }^{9}$

Following blocking with $5 \%$ normal goat serum (NGS) in $0.01 \mathrm{~m}$ phosphate buffered saline (PBS), pH 7.1, the serum samples were added at a dilution of $1: 200$ in 5\% NGS and the plates were incubated at $37^{\circ} \mathrm{C}$ for $60 \mathrm{~min}$. Tween and other detergents were avoided as both blocking and washing agents in order to conserve lipids on the external surface of the bacilli. ${ }^{29}$ The plates were washed with $1 \%$ BSA in PBS and antihuman immunoglobulin-horseradish peroxidase (HRP) conjugate (Sigma, Poole, Dorset, UK) was added at a 1:1000 dilution in PBS. In some assays classspecific second antibody was used: in others, polyvalent second antibody was employed. The peroxidase substrate, o-phenylene-diamine (O-PD), was prepared freshly for each experiment as a $0.4 \mathrm{mg} / \mathrm{ml}$ solution in citrate phosphate buffer $\left(\mathrm{pH} \mathrm{5.0)}{ }^{21}\right.$ Hydrogen peroxide was added immediately before use at a concentration of $0.05 \%$. The reaction was stopped after 30 -min incubation with $2.5 \mathrm{~N}$ sulphuric acid.

\section{ELISA using BSA glycoconjugate}

The ELISA method developed by Brett et al. ${ }^{21}$ (Batch No. 11, provided by Dr R J W Rees) uses a glycoconjugate of BSA which mimics the $M$. leprae-specific epitope of PGLl and consists of the intact terminal disaccharide of the natural antigen linked to BSA by reductive amination. Since no lipid is present, coating of the antigen onto the plates is easier and there is no need to avoid the use of detergents such as Tween in the assay method. To reduce levels of nonspecific IgM binding in control wells without the glycoconjugate, the method was modified slightly by changing the diluent used with test samples from the BSA/Tween/PBS wash to $5 \%$ normal goat serum $+0 \cdot 5 \%$ Tween 20 in PBS, $\mathrm{pH} 7 \cdot 2$.

Analysis of Results. Since O-PD was used as the substrate in both ELISAs, the results were expressed as the absorbance at $490 \mathrm{~nm}$, measured using a Dynatech MR580 MicroELISA autoreader. The results from individual patients are expressed as the mean absorbance of triplicate wells coated with $M$. leprae minus the absorbance of a single well which did not contain $M$. leprae.

Triplicate antigen-coated wells were used in preference to duplicate wells to produce data from each experiment which could be used to assess the variability of the results. The background absorbance in control wells without bacteria was $<30 \%$ of the serum standard and the coefficient of variation $(\mathrm{CoV})$ in the results from uncoated or coated wells was $<15 \%$. There was less variation of the results in the BSA glycoconjugate ELISA $(\mathrm{CoV}<5 \%)$, probably attributable to the more reliable coating obtained with a soluble antigen. Since it was desirable to perform simultaneous assays on all of the sera at once and only 11 plates could be physically handled in one ELISA, single uncoated wells were used to estimate the background absorbance with each sample. 
Comparison of the ability of the various ELISAs to discriminate between patients and nonpatients was performed by defining a a arbitrary cut-off point as the absorbance at which $95 \%$ of the healthy subjects would be regarded as negative. Approximately $5 \%$ of the healthy contacts of leprosy patients are likely to be developing the disease at any one time,$^{30}$ although the exact figure will vary between different geographical areas. Alternative methods for the assessment of ELISA positivity rely upon data from a disease-free control population from the same area as the test population, a requirement which was not available in this study. ${ }^{31}$

The results were analysed using SPSS, version $\mathrm{H}$, release $9 \cdot 1$, on a DEC10 mainframe computer and Statgraphics, version 2.0 (STSC, California, USA). Since results from the ELISAs did not conf orm to a normal distribution, the relationship between individual ELISAs was examined using the Spearman rank correlation coefficient.

\section{Results}

The results of ELISAs for antibody of $\operatorname{IgG}$, IgM, and $\operatorname{IgA}$ subclasses directed against $M$. leprae in each group of subjects are shown in Figure 1(a), (b) and (c) respectively. The highest absorbances at $490 \mathrm{~nm}$ occurred in ELISAs for IgG antibody against $M$. leprae in sera from patients, with few positive results in the other groups. The absorbances for IgM and IgA antibodies were considerably lower and did not show good separation of patients from healthy subjects. ELISAs to detect polyvalent antibody against whole $y$-irradiated $M$. scrofulaceum and $M$. tuberculosis in serum were also performed (Figure 2(a) and (b)). These show some separation of the groups with high levels of antibody in many of the patients and relatively few positive results in the healthy subjects. The difference is most marked in the assay with $M$. tuberculosis as antigen.

The results of the ELISA for IgM against the BSA glycoconjugate are shown in Figure 2(c): there are many patient sera with high absorbances and there are also occasional positive results among the healthy contacts. High levels of IgG and IgA against this epitope of PGL1 were found in the patient groups, but none in the healthy subjects (results not shown). However, the absorbances in the IgM ELISA with BSA glycoconjugate were much higher at the same serum dilution than the $\mathrm{IgG}$ and IgA assays.

Comparison of the whole cell ELISA results against grade on the Ridley-Jopling scale ${ }^{32,33}$ for sera from the treated and untreated patients shows no convincing pattern in the ELISAs for IgG against $M$. leprae (Figure 3(a)) or in the other immunoglobulin subclasses, but there is a graded antibody response across the spectrum with $M$. tuberculosis (Figure 3(b)) and M. scrofulaceum, with the highest levels in the lepromatous patients. There is also a graded response in the ELISA for serum IgM against BSA-glycoconjugate (Figure 3(c)), which is less marked in the IgG assay and least strong in the $\operatorname{IgA}$ assay. Furthermore, when the results for the treated lepromatous patients are compared with the untreated patients, the absorbances in the treated group appear to be lower, although this apparent diminution in the IgM response to BSA-glycoconjugate is not statistically significant.

Correlation of the results from each individual for the different assays performed using the Spearman rank correlation coefficient reveals the existence of some relationships between the assay results, although in many cases these are not particularly strong. The results from different immunoglobulin subclasses for whole $M$. leprae correlate poorly within the study population and within the subject groups. There is a small correlation between the results from the BSAglycoconjugate ELISAs for different immunoglobulin subgroups, suggesting that the results with whole $M$. leprae are complicated by the different degree of response within each immunoglobulin subgroup to the many antigens present in the ELISA using whole mycobacteria. Good correlation $(r=0.59, p<0.0001)$ was observed between the responses to whole $M$. tuberculosis and whole $M$. scrofulaceum in the study population. This is presumably due to extensive similarity between the surface antigens of these two species. 
(a)

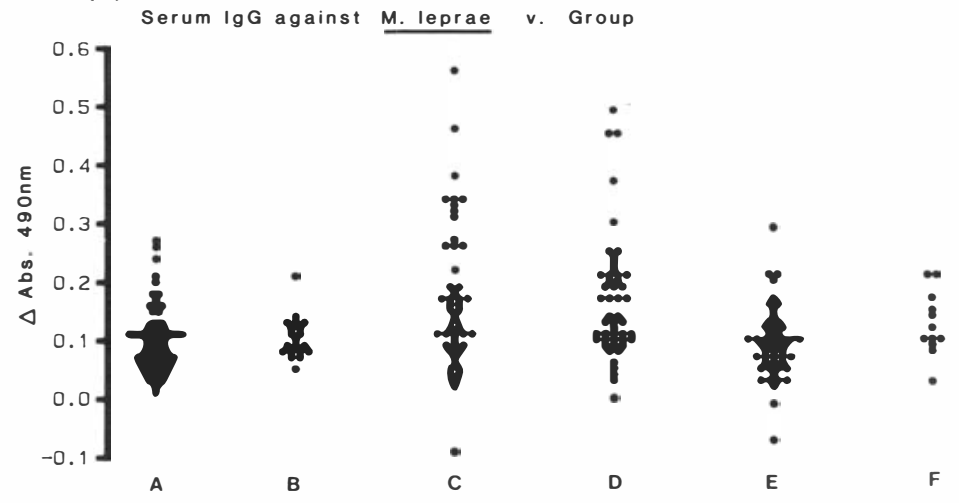

(b)

Serum IgM against M. leprae v. Group

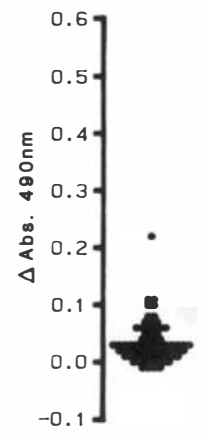

A

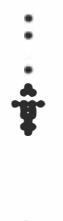

B

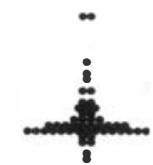

C
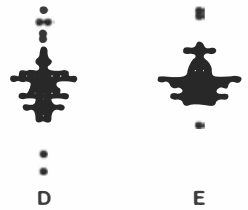

(c)

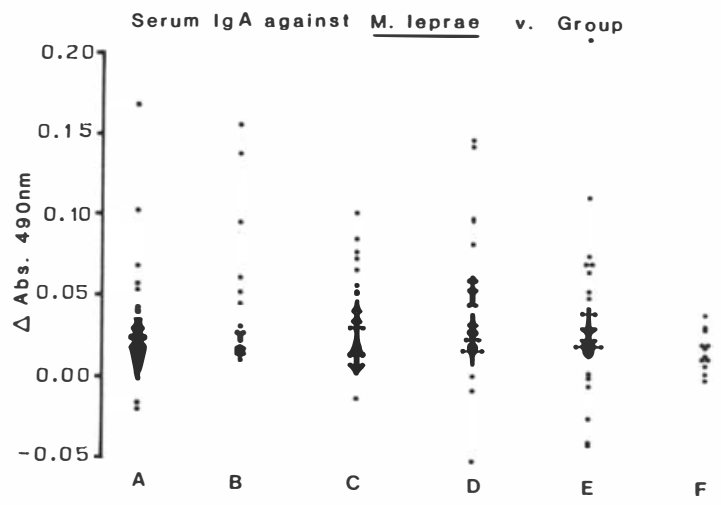

Figure 1. Serum antibody responses to whole $y$-irradiated $M$. leprae for each subject group: (a) IgG, (b) IgM, and (c) IgA subclasses. A, household contacts; B, hospital contacts; C, untreated patients; D, treated patients; E, 'control' group; F, Dundee controls. 
(a)

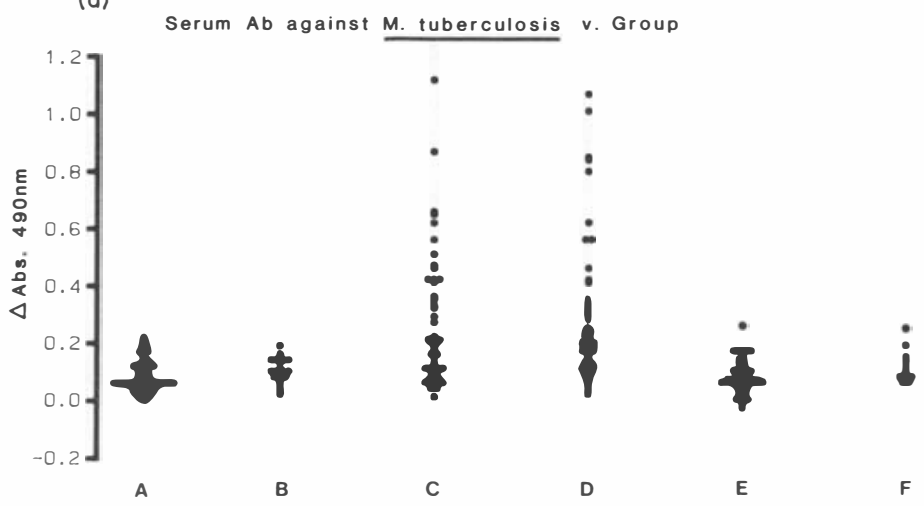

(b)

Serum $A b$ against M. scrofulaceum v. Group

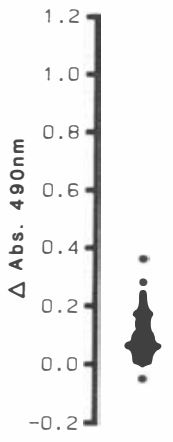

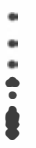

B

C

D

(c)
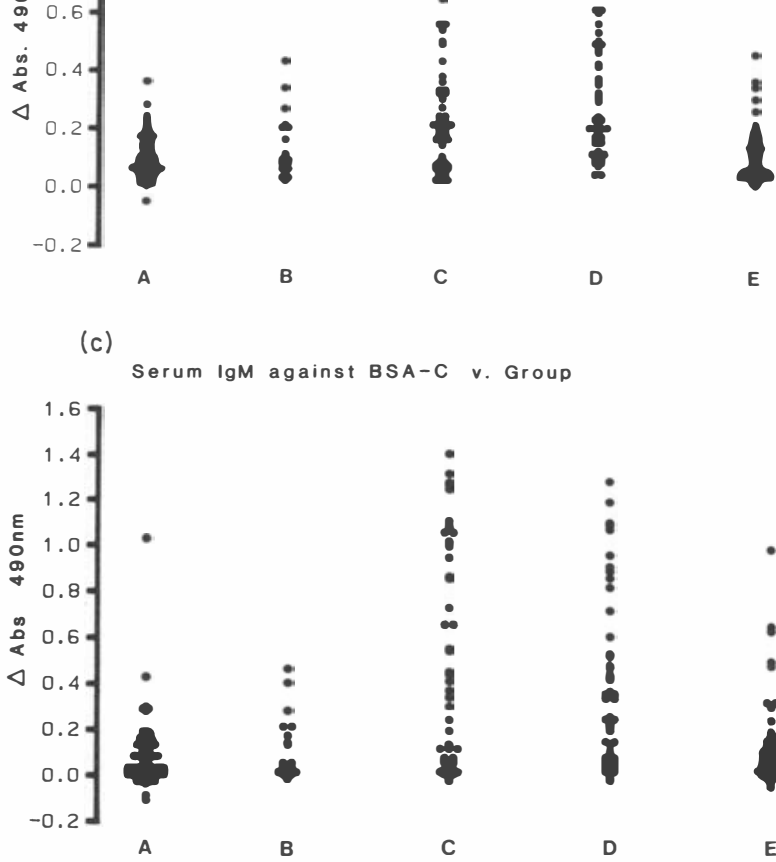

E

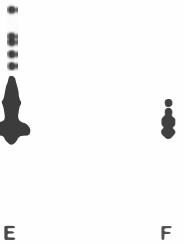
scrofulaceum, and (c) BSA glycoconjugate $11^{21}$ (IgM subclass) in each subject group. A, household contacts; b, hospital contacts; C, untreated patients; D, treated patients; E, 'control' group; F, Dundee controls. 
(a)

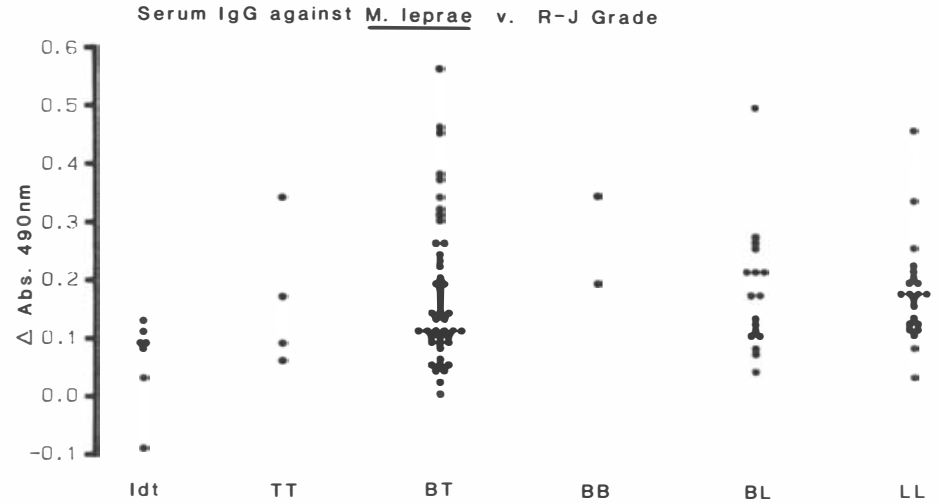

(b)

Serum Ab against M. tuberculosis V. R-J Grade

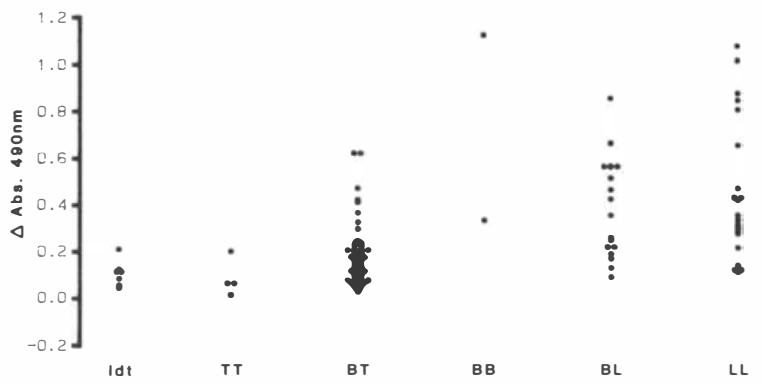

(c)

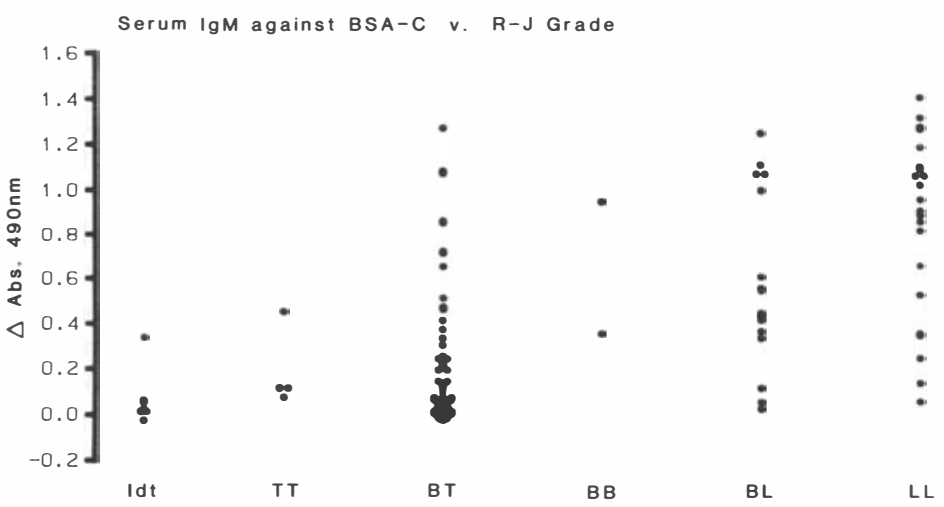

Figure 3. Serum antibody responses to (a) whole $y$-irradiated $M$. leprae (IgG subclass), (b) whole $y$-irradiated $M$. tuberculosis H37Rv (all subclasses) and (c) BSA glycoconjugate $11^{21}$ (IgM subclass) for treated and untreated patients classified on the Ridley-Jopling scale. 
Table 1. The percentages of positive responders to each serum ELISA in each subject group

\begin{tabular}{lcrrrrr}
\hline & & \multicolumn{5}{c}{ Subject group } \\
\cline { 3 - 7 } ELISA & $\begin{array}{c}\text { Cut-off } \\
\text { value }\end{array}$ & $\mathrm{A}$ & $\mathrm{B}$ & $\mathrm{C}$ & $\mathrm{D}$ & $\mathrm{E}$ \\
\hline IgG to ML & $0 \cdot 207$ & 5 & 5 & 28 & 29 & 6 \\
IgM to ML & $0 \cdot 112$ & 4 & 17 & 8 & 10 & 6 \\
IgA to ML & $0 \cdot 075$ & 3 & 15 & 6 & 10 & 6 \\
IgG to BSA-C & $0 \cdot 017$ & 4 & 10 & 34 & 26 & 6 \\
IgM to BSA-C & $0 \cdot 429$ & 3 & 5 & 46 & 34 & 10 \\
IgA to BSA-C & $0 \cdot 016$ & 6 & 0 & 38 & 30 & 8 \\
Ab to TB & $0 \cdot 173$ & 8 & 5 & 52 & 60 & 2 \\
Ab to SC & $0 \cdot 276$ & 3 & 10 & 32 & 46 & 8 \\
$n$ & - & 71 & 20 & 50 & 50 & 50 \\
\hline & & & & & & \\
\hline
\end{tabular}

A, Household contacts; B, Hospital contacts; C, Untreated patients; D, Treated patients; E, Indigenous 'control' group.

$\mathrm{ML}, M$. leprae; BSA-C, BSA glycoconjugate; TB, M. tuberculosis; SC, M. scrofulaceum; $n$, Number of subjects (missing values excluded).

NB. The $95 \%$ limit was calculated by taking the 8th highest value of the results from the healthy subject groups (A, B and E) as the cut-off value.

When all of the subjects are considered together, the IgG response to $M$. leprae shows significant correlation with the serum antibody response to both $M$. tuberculosis $(r=0.46, p<0.0001)$ and $M$. scrofulaceum $(r=0.38, p<0.0001)$. The correlations are of similar strength in the untreated patient group $(r=0.47, p<0.001$ and $r=0.36, p<0.01)$, but only the antibody response to $M$. tuberculosis correlates significantly in the treated patient group $(r=0.31, p<0.05)$ and there are no significant differences in the healthy subject groups. These observations may be attributable to cross-reaction between different species in the whole microbial cell ELISA, but there is also a significant correlation between the serum antibody response to $M$. tuberculosis or $M$. scrofulaceum and the IgM response to BSA-glycoconjugate from all the subjects $(r=0.47, p<0.0001$ and $r=0.41$, $p<0.0001$ respectively). Stronger correlations between the results of these ELISAs also occur in the untreated patients $(r=0 \cdot 68, p<0 \cdot 0001$ and $r=0 \cdot 52, p=0.0003$ respectively), but not in the other subject groups. There was no correlation between the serum IgM response to BSA-glycoconjugate and the serum IgM response to whole $M$. leprae, although there was some correlation with the IgG and $\operatorname{IgA}$ responses to $M$. leprae ( $r=0.34, p<0.001$ and $r=0.17, p<0.008$ respectively).

The percentage of positive antibody responses for each group was estimated using a cut-off point calculated by regarding $95 \%$ of the individuals in the normal subject groups as negative. The results are shown in Table 1 . The assays offering the best discrimination between patients and healthy subjects were: 1 , IgG to whole M. leprae; 2 IgM to BSA glycoconjugate; and 3 , antibody of any subclass to whole $M$. tuberculosis. However none were able to distinguish reliably between healthy subjects and paucibacillary patients.

\section{Discussion}

The two ELISAs employed in this study allowed the detection of antibody against $1 \mathrm{M}$. leprae- 
specific glycolipid epitope on the surface of the organism and against a wide variety of antigens expressed on the surface of 3 mycobacterial species. This contrast was designed to give an overview of the humoral responses to $M$. leprae and other mycobacteria in each subject group.

The results of the present ELISA studies to whole $y$-irradiated mycobacteria are similar to those found by other workers using whole bacilli as antigen ${ }^{8,10,29}$ More of the subjects produce an IgG response than either IgM or IgA and the absorbances in the IgG ELISA are higher than they are for the other classes of immunoglobulin. Moreover, the subjects show a similar response to other species of mycobacteria (in this case, M. tuberculosis and M. scrofulaceum), confirming the findings of Douglas et al..$^{10}$ In patients, the lack of a graded antibody response to $M$. leprae across the spectrum of disease from TT to LL (Figure 3(a)) is probably in part due to the inclusion of treated patients in the results, although there is certainly great variation in the antibody response within each grade and some untreated lepromatous patients show low levels of antibody activity in all of the ELISAs (Figures 3(a), (b) \& (c)).

The serum IgM response to BSA glycoconjugate $11^{21}$ is considerably greater than the $\operatorname{IgG}$ or IgA response. This is in keeping with the results of other studies using PGLl or synthetic glycoconjugates, ${ }^{21,22}$ all of which have shown that the IgM response to this determinant is immunodominant.$^{19}$ However, it appears that several of the hospital contacts have a significant titre of IgM antibody to the BSA conjugate in their serum (Figure 2(c)) which may reflect chronic exposure to $M$. leprae. Thus chronic exposure as well as infection may be important in producing serological antibody responses to this particular antigen and this may complicate attempts to use this ELISA as a serological tool for diagnosis. Many of the treated patients in this study had only been treated for a few months and it is theref ore not surprising that few differences between treated and untreated patients are apparent in the ELISA results.

Correlation of the various ELISA results for individual subjects shows that there is linkage between the antibody responses to $M$. leprae and $M$. tuberculosis. The same is true of $M$. leprae and $M$. scrofulaceum, but to a lesser extent. Since there is considerable difference between the surface antigens of $M$. leprae and $M$. tuberculosis, the explanation may lie in the host response to common external antigens. However, the smallest correlation between the whole mycobacterial assays and the BSA-glycoconjugate assay occurred with $M$. leprae and the strongest with $M$. tuberculosis. Induction of cross-reactive antibodies might explain this, but infection with $M$. leprae could also produce general stimulation of immunological memory for mycobacterial antigens resulting in coresponses to antigens belonging to other mycobacteria. Such a link might well have survival value, since exposure to different, antigenically related organisms is an everyday occurrence. Further evidence for 'co-responsiveness' may come from specific assays for antibody responses to individual antigenic determinants specific to different species of related mycobacteria. ${ }^{34} \mathrm{~A}$ similar phenomenon, known as 'original antigenic sin,' has been described by Ivanyi. ${ }^{35}$

The serum antibody response to external antigens of $M$. leprae is a complex one, with many antigens involved, some of which cross-react with other mycobacterial species. Responses to different antigens may be dominant in the different immunoglobulin subclasses. These differences have already proved usef ul in the development of tests for subclinical leprosy and may be exploited further. In this study, the response to $M$. tuberculosis offered the best discrimination between patients and healthy subjects with a $55 \%$ sensitivity at $95 \%$ specificity. ${ }^{36}$ Addition of other responses to form an index does not significantly improve the sensitivity, due to their correlation with the $M$. tuberculosis response and their low intrinsic sensitivity. Antigen capture assays using monoclonal antibodies may provide a better alternative for early diagnosis of leprosy, since these do not depend upon the host response to the infection. ${ }^{37-39}$

\section{Acknowledgments}

We wish to thank Dr I H Cochrane, Mr S Halda, Dr T Ali and Dr M S Islam for their assistance in 
Bangladesh and Mr R Fawkes for preparing the figures. We are gratef ul to Professor C du Florey for help in analysing the data. IAC was supported by the award of the Becton-Dickinson Travelling Scholarship by the Royal College of Pathologists and by LEPRA.

\section{References}

1 Lewis PA, Aronson JD. The complement fixation test as applied to leprosy. J Exp Med, 1923; 38: $219-32$.

2 Ross H. An evaluation of the Maillard-Gagliardo complement fixation test in leprosy. Int J Lepr, 1954; 22: 328-30.

3 Middlebrook G, Dubos RF. Specific serum agglutination of erythrocytes sensitised with extracts of tubercle bacilli. $J$ Exp Med, 1948; 88: 521-8.

${ }^{4}$ Ross H. The results of a modified Middlebrook-Dubos hemagglutination test in leprosy; 261 cases. Int $J$ Lepr, 1954; 22: 174-80.

5 Navalkar RG. Immunologic analysis of Mycobacterium leprae antigens by means of diffusion-in-gel methods. Int J Lepr, 1971; 39: 105-12.

${ }^{6}$ Melsom R. Serodiagnosis of leprosy: the past, the present and some prospects for the future. Int J Le pr, 1983; 51: $235-52$

7 Abe M, Minagawa F, Yoshino Y, Ozawa T, Saikawa K, Saito T. Fluorescent leprosy antibody absorption test for detecting subclinical inf ection with Mycobacterium leprae. Int J Lepr, 1980; 48: 109-19.

8 Touw J, Langendijk EMJ, Stoner JL, Belehu A. Humoral immunity in leprosy: immunoglobulin G and $\mathbf{M}$ antibody responses to Mycobacterium leprae in relation to various disease patterns. Infect Immun, 1982; 36: 885-92.

9 Douglas JT, Naka SO, Lee JW. Development of an ELISA for detection of antibody in leprosy. Int J Lepr, 1984; 52: 19-25.

10 Douglas JT, Worth RM. Field evaluation of an ELISA for detection of antibody in leprosy. Int J Lepr, 1984; 52: $26-33$.

$"$ Harboe M, Closs O, Bjune G, Kronvall G, Axelsen NH. Mycobacterium leprae specific antibodies detected by radioimmunoassay. Scand J Immunol, 1978; 7: 111-20.

12 Young DB, Buchanan TM. A serological test for leprosy with a glycolipid specific for Mycobacterium leprae. Science, 1983; 221: 1057-9.

${ }^{13}$ Kronvall G, Bjune G, Stanford JL, Menzel S. Samuel D. Mycobacterial antigens in antibody responses of leprosy patients. Int J Lepr, 1975; 43: 299-306.

${ }^{14}$ Harboe M, Closs O, Bjorvatn B, Kronvall G, Axelsen NH. Antibody response in rabbits to immunisation with Mycobacterium leprae. Infect Immun, 1977; 18: 792-805.

15 Closs O, Mshana RN, Harboe M. Antigenic analysis of Mycobacterium leprae. Scand J Immunol, 1979; 9: 297-302.

${ }^{16}$ Harboe M. The immunology of leprosy. In: Leprosy. Hastings RC (ed.), Edinburgh: Churchill Livingstone, 1985, Ch. 4, 53-87.

17 Melsom R. Naafs B, Harboe M, Closs O. Antibody activity against Mycobacterium leprae antigen 7 during the first year of DDS treatment in lepromatous (BL-LL) leprosy. Lepr Rev, 1978; 49: 17-29.

18 Hunter SW, Brennan PJ. A novel phenolic glycolipid from Mycobacterium leprae possibly involved in immunogenicity and pathogenicity. J Bacteriol, 1981; 147: 728-35.

19 Young DB, Dissanayake S, Miller RA, Khanolkar SJ, Buchanan TM. Humans respond predominantly with IgM immunoglobulin to the species-specific glycolipid of Mycobacterium leprae. J Infect Dis, 1984; 149: $870-3$.

${ }^{20}$ Melsom R, Harboe M, Naafs B. Class specific anti-M. leprae antibodies assay in lepromatous (BL-LL) leprosy patients during the first two to four years of DDS treatment. Int J Le pr, 1982; 50: 271-81.

${ }^{21}$ Brett SJ, Payne SN, Gigg J, Burgess P, Gigg R. Use of synthetic glycoconjugates containing the Mycobacterium leprae specific and immunodominent epitope of phenolic glycolipid I in the serology of leprosy. Clin exp Immunol 1986; 64: 476-83.

22 Cho SN, Chatterjee D, Brennan PJ. A simplified serological test for leprosy based on a 3, 6-di-Omethyglycose-containing synthetic antigen. Am J Trop Med Hyg, 1986; 35: 167-72.

${ }^{23}$ Sinha S, Sengupta U, Ramu G, Ivanyi J. A serological test for leprosy based on competitive inhibition of monoclonal antibody binding to the MY2a determinant of Mycobacterium leprae. Trans R Soc Trop Med Hyg, 1983; 77: 869-71.

${ }^{24}$ Sinha S, Sengupta U, Ramu G, Ivanyi J. Serological survey of leprosy and control subjects by a monoclonal antibody-based immunoassay. Int J Lepr, 1985; 53: 33-6.

25 Klatzer PR, De-Wit MY, Kolk AH. An ELISA-inhibition test using monoclonal antibody for the serology of leprosy. Clin Exp Immunol, 1985; 62: 468-73.

26 Editorial. Serological tests for leprosy. Lancet, 1986; 1: 533-5. 
27 Cree IA, Smith WCS, Rees RJW, Beck JS. The influence of anti-mycobacterial chemotherapy on delayed hypersensitivity skin-test reactions in leprosy patients. Le pr Rev, 1988; 59: 145-51.

${ }^{28}$ Czerkinsky C, Rees AS, Bergmeier LA, Challacombe SJ. The detection and specificity of class-specific antibodies to whole bacterial cells using a solid phase radioimmunoassay. Clin Exp Immunol, 1983; 53: 192-200.

29 Buchanan TM, Young DB, Miller RA, Khanolkar SR. Serodiagnosis of infection with Mycobacterium leprae. Int J Lepr, 1983; 51: 524-30.

30 Noordeen SK. The epidemiology of leprosy. In: Leprosy, Hastings RC (ed), Edinburgh: Churchill Livingstone, 1985, Ch. 2, 15-30.

${ }^{31}$ Kurstak E. Progress in Enzyme Immunoassays: production of reagents, experimental design, and interpretation. Bull WHO, 1985; 63, 793-811.

32 Ridley DS, Jopling WH. Classification of leprosy according to immunity. A five group system. Int $J$ Lepr, 1966; 34: 255-73.

33 Ridley DS. Histological classification and the immunological spectrum of leprosy. Bull WHO, 1974; 51: 45165.

${ }^{34}$ Bothamley G, Beck JS, Agusni I, Ilias MI, Kardjito T, Grange JM, Ivanyi J. Antibodies to Mycobacterium tuberculosis in leprosy. Lancet, 1987; i: 1098.

35 Ivanyi J. Recall of antibody synthesis to the primary antigen following successive immunisation with heterologous albumins. A two cell theory of the original antigenic sin. Eur J Immunol, 1972; 2: 354-59.

${ }^{36}$ Kronvall G. The potential of immunological tests as tools in the epidemiology of leprosy. Lepr Rev, 1981; 51: (Suppl. 1), 207-19.

37 Praputpittaya K, Ivanyi J. Detection of an antigen (MY4) common to M. tuberculosis and M. leprae by tandem immunoassay. J Immunol Methods, 1985; 79: 149-57.

38 Young DB, Harnisch JP, Knight J, Buchanan TM. Detection of phenolic glycolipid I in sera from patients with lepromatous leprosy. J Infect Dis, 1985; 152: 1078-81.

39 Kaldany RRJ, Nurlign A. Development of a dot-ELISA for detection of leprosy antigenuria under field conditions. Lepr Rev, 1986; 57: (Suppl 2), 95-100. 